\title{
A first-in-human dose-escalation study of ME-143, a second generation NADH oxidase inhibitor, in patients with advanced solid tumors
}

\author{
Shubham Pant • Howard A. Burris III - Kathleen Moore • \\ Johanna C. Bendell • Carla Kurkjian - Suzanne F. Jones • \\ Ofir Moreno • John G. Kuhn • Scott McMeekin • \\ Jeffrey R. Infante
}

Received: 9 January 2013 / Accepted: 7 March 2013 /Published online: 24 March 2013

(C) The Author(s) 2013. This article is published with open access at Springerlink.com

\begin{abstract}
Summary Background ME-143, a second-generation tumor-specific NADH oxidase inhibitor, is broadly active against human cancers in vitro and in vivo. This first-inhuman dose-escalation study evaluated the dose-limiting toxicities (DLTs), pharmacokinetics, safety, tolerability, and preliminary anti-tumor activity of ME-143 in patients with advanced solid tumors. Methods Patients with advanced solid tumors were treated in a $3+3$ escalation design. ME-143 was administered via intravenous infusion on days 1,8 , and 15 of the first 28 -day cycle, and weekly thereafter; the final cohort received twice-weekly treatment. Samples for pharmacokinetic analysis were collected during cycle 1 .
\end{abstract}

Previous presentations 2012 American Society of Clinical Oncology Annual Meeting - Kurkjian et al, J Clin Oncol 30, 2012 (suppl; abstr 3067)

S. Pant $\cdot$ K. Moore $\cdot$ C. Kurkjian $\cdot$ S. McMeekin

SCRI, University of Oklahoma,

Oklahoma City, OK, USA

H. A. Burris III $\cdot$ J. C. Bendell $\cdot$ J. R. Infante $(\square)$

SCRI, Tennessee Oncology, PLLC,

3322 West End Avenue, Suite 900,

Nashville, TN 37203, USA

e-mail: jinfante@tnonc.com

S. F. Jones

SCRI, Nashville, TN, USA

O. Moreno

MEI Pharma, Inc, San Diego,

CA, USA

J. G. Kuhn

University of Texas, College of Pharmacy,

Austin, TX, USA
Treatment continued until disease progression or unacceptable toxicity. Results Eighteen patients were treated: $2.5 \mathrm{mg} / \mathrm{kg}$ $(n=3) ; 5 \mathrm{mg} / \mathrm{kg}(n=3) ; 10 \mathrm{mg} / \mathrm{kg}(n=3) ; 20 \mathrm{mg} / \mathrm{kg}(n=6)$; $20 \mathrm{mg} / \mathrm{kg}$ twice-weekly $(n=3)$. There were no DLTs observed. Nearly all treatment-related toxicities were grade $1 / 2$, specifically (all grades) nausea (22\%) and fatigue (17\%). Two patients experienced infusion reactions at the $20 \mathrm{mg} / \mathrm{kg}$ dose level, one of which was grade 4 . Stable disease was documented in three patients with colorectal cancer, cholangiocarcinoma, and anal cancer. Pharmacokinetic exposures were linear and dosedependent, with a half-life of approximately $5 \mathrm{~h}$. Conclusions ME-143 was well-tolerated when administered intravenously at the maximally administered/recommended phase 2 dose of $20 \mathrm{mg} / \mathrm{kg}$ once weekly to patients with advanced solid tumors. Though limited clinical activity was observed with monotherapy, inhibitors of tumor-specific NADH oxidase such as ME-143 may derive their greatest benefit in combination with cytotoxic chemotherapy.

Keywords ME-143 - tNOX · Dose escalation · Isoflavone · Apoptosis

\section{Introduction}

Isoflavone derivatives are a class of small molecule inhibitors with unique anti-cancer properties. These compounds selectively bind to a tumor-specific, splice variant form of NADH oxidase (tNOX) as compared with constitutively expressed $\mathrm{NADH}$ oxidase in normal cells. In tumor cells, the binding of tNOX shifts the ceramide-S1P equilibrium resulting in prompt apoptosis via pleotropic caspase activation [1]. Phenoxodiol is 
the most well studied molecule in this class having been administered to over 200 patients in both oral and intravenous formulations [MEI Pharma, Inc, data on file]. Overall phenoxodiol is well-tolerated with limited side effects [2]. No dose-limiting toxicities were observed when given intravenously, however diarrhea is limiting with the oral administration [2]. In a phase II study of intravenous phenoxodiol in combination with cisplatin or paclitaxel for women with epithelial ovarian, fallopian tube, or primary peritoneal cancers, three of $16(19 \%)$ platinumrefractory ovarian cancer patients had a partial response with $9(56 \%)$ patients achieving stable disease [3]. A subsequent phase III study evaluating an oral formulation of phenoxodiol in combination with carboplatin in patients with platinum-refractory ovarian cancer did not meet its primary endpoint of improved progression-free survival (clinicaltrials.gov, NCT00382811; MEI Pharma, Inc, data on file); however, these results may be confounded by bioavailability issues with the oral formulation.

ME-143 is a synthetic second-generation tNOX inhibitor. It is an analogue of the first generation compounds phenoxodiol and triphendiol, but with significantly greater potency with in vitro $\mathrm{IC}_{50}$ 's generally $<1 \mu \mathrm{M}$. After binding to tNOX, ME-143 has been shown in preclinical studies to cause tumor cell-specific inhibition of plasma membrane electron transport (pMET), inhibition of AKT phosphorylation, inactivation of the x-linked inhibitor of apoptosis protein (XIAP), and induction of caspasedependent apoptosis through both extrinsic and intrinsic pathways $[4,5]$. Dose dependent inhibition of human tumor xenograft growth was seen in mice, with a growth inhibition plateau between $50-100 \mathrm{mg} / \mathrm{kg}$ [MEI Pharma Inc, data on file]. A dose of $100 \mathrm{mg} / \mathrm{kg}$ in mice with an AUC of $\sim 20,000 \mathrm{ng} * \mathrm{~h} / \mathrm{mL}$ correlates to a human dose and potential target of approximately $18 \mathrm{mg} / \mathrm{kg}$. The only significant laboratory findings in rats and dogs were dose dependent reduction in urinary sperm counts, and atrophy of the testis and epididymis (noted in the rat studies). The defined no observed adverse effect level (NOAEL) was $8 \mathrm{mg} / \mathrm{kg}$. While there was no defined severely toxic dose (STD), including the highest dose level of $140 \mathrm{mg} / \mathrm{kg}$, the starting dose of ME-143 in this study was $2.5 \mathrm{mg} / \mathrm{kg}$, approximately $10 \%$ of the maximal dose delivered to animals. A weekly IV dosing schedule was selected based on the evidence of activity generated in phase II studies of phenoxodiol in ovarian cancer [3].

The primary objectives of this first-in-human phase 1 dose escalation trial were to determine the tolerability, adverse event profile, and dose-limiting toxicities (DLTs) of ME-143. Secondary objectives included assessments of the pharmacokinetic (PK) profile and preliminary antitumor activity of ME-143 observed in patients with refractory solid tumors.

\section{Patients and methods}

This phase 1, open-label, non-randomized, dose-escalation (Clinicaltrials.gov, NCT01401868) was approved by the institutional review boards of both participating sites: Sarah Cannon Research Institute/Tennessee Oncology, PLLC (Nashville, TN), and University of Oklahoma (Oklahoma City, OK). All patients provided written informed consent. The study was conducted in accordance with all applicable regulatory guidelines and under the guidance of the Declaration of Helsinki [6].

Patient selection

Adult patients with advanced cancer for which there were no standard therapeutic alternatives and Eastern Cooperative Oncology (ECOG) performance status of 0 or 1 were included. Other eligibility criteria included: life expectancy of $\geq 12$ weeks; $\geq 4$ weeks since last anti-cancer therapy and 21 days since last radiotherapy, immunotherapy or surgery ( $\geq 14$ days for limited palliative radiotherapy). Adequate bone marrow, hepatic, and renal function for study inclusion were defined as: absolute neutrophil count $(\mathrm{ANC})>1.5 \times 10^{9} / \mathrm{L}$; platelets $>100 \times 10^{9} / \mathrm{L}$; hemoglobin $>9 \mathrm{~g} / \mathrm{dL}$; bilirubin $\leq 1.5$ times the institutional upper limit of normal (ULN); aspartate transaminase (AST) and alanine transaminase (ALT) $\leq 2.5 \mathrm{x}$ ULN, or $<5 x$ ULN for patients with liver metastases; creatinine $\leq 1.5 \mathrm{x}$ ULN. Women were required to have a follicle stimulating hormone (FSH) level within normal limits and those of child-bearing potential must have had a negative serum pregnancy test. Men were required to have a detectable level of testosterone.

Patients with active central nervous system (CNS) metastases were excluded; however, those with treated CNS metastases could be enrolled after approval of the medical monitor. Additional exclusion criteria were: uncontrolled infection or systemic disease; cardiac disease not well controlled or myocardial infarction within the last 12 months; average QTc from triplicate electrocardiograms (ECGs) $\geq 470 \mathrm{msec}$; hypersensitivity to ME-143 or components; human immunodeficiency virus (HIV) or Hepatitis B or C (active, previously treated, or both); history of solid organ transplant; psychiatric, social, or geographic situations precluding study participation.

Treatment and dose modifications

Five cohorts were planned $(2.5 \mathrm{mg} / \mathrm{kg} ; 5 \mathrm{mg} / \mathrm{kg} ; 10 \mathrm{mg} / \mathrm{kg}$; $20 \mathrm{mg} / \mathrm{kg}$; MTD or $20 \mathrm{mg} / \mathrm{kg}$ twice weekly). Four cohorts were initially planned for once weekly administration of ME-143 at $2.5 \mathrm{mg} / \mathrm{kg}, 5 \mathrm{mg} / \mathrm{kg}, 10 \mathrm{mg} / \mathrm{kg}$, and $20 \mathrm{mg} / \mathrm{kg}$. The protocol was amended (12/21/2011) to enroll a fifth cohort with twice-weekly dosing once the weekly cohorts were completed. 
ME-143 was formulated with Captisol ${ }^{\mathrm{TM}}$ in water, with each $10 \mathrm{~mL}$ vial containing $35 \mathrm{mg} / \mathrm{mL}$ of ME-143 and $300 \mathrm{mg} / \mathrm{mL}$ of Captisol (ratio approximately 1:8.6), and was diluted with saline prior to administration as an intravenous (IV) infusion over $30 \mathrm{~min}$ on days 1,8 , and 15 of cycle 1 (28 days). In subsequent cycles, ME-143 was administered weekly with no week of rest. In the twice-weekly dosing cohort, patients received IV ME-143 on days 1, 2, 8, $9,15,16$, and were evaluated on day 22 with 1 week of rest (cycle 1). In subsequent cycles, ME-143 was administered on 2 consecutive days weekly (days 1, 2, 8, 9, 15, 16, 22, and 23). Treatment continued until progression or unacceptable toxicity and no intra-patient escalation was permitted.

Each treatment cohort was designed to enroll 3-6 patients. Following a $3+3$ design [7], a decision to enroll patients at the next dose level was made once the last evaluable patient completed one cycle of ME-143 at their allocated dose level. Toxicities were graded using National Cancer Institute Common Terminology Criteria for Adverse Events (CTCAE version 4.03) [8]. DLTs were defined as any of the following during cycle 1: grade $\geq 3$ neutropenia for $\geq 5$ days; febrile neutropenia; grade 4 thrombocytopenia or grade 3 thrombocytopenia with bleeding; any grade $\geq 3$ abnormal lab values assessed as clinically significant; any grade $\geq 3$ non-laboratory toxicity (excluding rash, nausea, diarrhea, and vomiting if controlled by standard supportive therapy). Once the MTD was established, the protocol allowed an option to expand this cohort with the enrollment of an additional three to six additional patients.

\section{Assessments}

Patients underwent physical examinations with assessment of vital signs and ECOG performance status at screening, and weekly thereafter. Electrocardiograms (ECGs) were done in triplicate at screening, with single ECG measurements immediately post-dose on day 1 of each cycle (day 2 of each cycle twice-weekly dosing cohort). Complete blood counts, including differential and platelet count, and chemistry profiles were evaluated at baseline, days 1 and 15 of each cycle and at end of study. Urinalysis was performed at baseline, day 1 of each cycle, and end of study. FSH and testosterone (for women and men, respectively) were assessed at baseline and end of study. Patients were assessed for response to treatment, using the Response Evaluation Criteria in Solid tumors (RECIST 1.1) [9], at least every 12 weeks. Baseline radiology assessments were performed within 28 days (4 weeks) prior to the first dose of ME-143.

\section{Pharmacokinetics}

Blood samples for pharmacokinetic evaluation were collected during cycle 1 on days 1 and 15 at the following time points: pre-dose, just prior to the end of infusion, and $10 \mathrm{~min}, 20 \mathrm{~min}, 30 \mathrm{~min}, 1 \mathrm{~h}, 1.5 \mathrm{~h}, 2 \mathrm{~h}, 3 \mathrm{~h}, 4 \mathrm{~h}, 5 \mathrm{~h}, 6 \mathrm{~h}$ and $24 \mathrm{~h}$ post-dose. On the twice-weekly dosing cohort samples were collected at the same time points and on days 2 and 16 pre-dose and just prior to the end of infusion.

\section{Statistical analysis}

This study tested no formal hypotheses, and all analyses were descriptive and exploratory.

Peak concentrations $\left(\mathrm{C}_{\max }\right)$ and trough levels $\left(\mathrm{C}_{\min }\right)$ were determined by inspection of each individual's concentration-time curves. Terminal half-lives ( $t$ 1/2) were calculated by dividing 0.693 by the elimination rate constants. The area under the concentration-time curve (AUC) was calculated using the linear trapezoidal rule up to the last measurable time point $\left(\mathrm{AUC}_{0-24}\right)$, then extrapolated to infinity $\left(\mathrm{AUC}=\mathrm{AUC}_{0-24}+\mathrm{C}_{\text {last } / \mathrm{K}}\right)$. Systemic clearance (CL) was determined by dividing the dose by AUC. The apparent volume of distribution at steady-state (Vdss) was determined by the following relationship: Vdss $=($ Dose $\mathrm{X}$ AUMC/AUC2 $)-($ Dose $\mathrm{x}$ Duration of Infusion/ ( $2 \times \mathrm{AUC}$ ), where AUMC is the area under the moment curve extrapolated to infinity.

\section{Results}

\section{Patient characteristics}

Between September 2011 and August 2012, eighteen patients received at least one infusion of ME-143 (Table 1). The majority of the patients had an ECOG performance status of 0 (12 patients, $67 \%$ ), and colorectal cancer was the most common tumor type (8 patients, $44 \%)$. Nine patients $(50 \%)$ had received 4 or more prior chemotherapy regimens.

Dose escalation and safety

No DLTs were observed in the once weekly cohorts of 2 . $5 \mathrm{mg} / \mathrm{kg}, 5 \mathrm{mg} / \mathrm{kg}, 10 \mathrm{mg} / \mathrm{kg}$ and $20 \mathrm{mg} / \mathrm{kg}$ (Table 2). With no DLTs, the MTD was not exceeded and $20 \mathrm{mg} / \mathrm{kg}$ was the maximally administered dose. Three patients were enrolled in the twice-weekly cohort. One of the patients enrolled in this cohort had a grade 4 infusion reaction.

\section{Safety}

Treatment-emergent adverse events in $\geq 10 \%$ of patients are summarized by dose level in Table 3. The most frequently reported adverse events irrespective of relationship to $\mathrm{ME}$ 143 across all dose levels were fatigue (33\%), diarrhea (22\%), and nausea (22\%). Only seven patients experienced 
Table 1 Patient characteristics $(N=18)$

\begin{tabular}{ll}
\hline Characteristic & Number of Patients (\%) \\
\hline Median age, years (range) & $65(20-82)$ \\
Sex - female & $13(72 \%)$ \\
Race - Caucasian & $16(89 \%)$ \\
Baseline ECOG performance status & \\
0 & $12(67 \%)$ \\
1 & $6(33 \%)$ \\
Primary tumor type & \\
colorectal & $8(44 \%)$ \\
endometrial & $3(17 \%)$ \\
cholangiocarcinoma & $2(11 \%)$ \\
other & $5(28 \%)$ \\
Number of prior chemotherapy regimens & \\
1 & $1(6 \%)$ \\
2 or 3 & $8(44 \%)$ \\
4 or more & $9(50 \%)$ \\
Prior surgery & $3(17 \%)$ \\
Prior radiation & $3(17 \%)$ \\
\hline
\end{tabular}

${ }^{a}$ One patient each: small-cell lung, pancreas, sarcoma, squamous carcinoma of the anus, squamous carcinoma of the head and neck

adverse events deemed related to treatment with ME-143 and with the exception of the grade 4 infusion reaction described below, these were all grade 1 or 2 . There were no clinically significant changes in testosterone or FSH levels. Three patients experienced serious adverse events determined to be unrelated to ME-143 treatment; one patient with grade 3 paroxysmal supraventricular tachycardia $(20 \mathrm{mg} / \mathrm{kg}$ weekly) and two patients with grade 3 pneumonia (both $2.5 \mathrm{mg} / \mathrm{kg}$ ).

The only adverse events that required treatment discontinuation were the two patients who experienced infusion reactions related to ME-143. One patient experienced a grade 2 infusion reaction during her first $20 \mathrm{mg} / \mathrm{kg}$ twiceweekly treatment with ME-143. During the first infusion, the patient developed a headache and nausea; symptoms resolved following infusion interruption, and the patient was able to complete the dose without recurrence. On day 2 , the patient's infusion was interrupted due to the development of chest pressure, headache, nausea, and flushing, but was eventually completed.

A second patient experienced a grade 4 infusion reaction during her 8th weekly treatment with ME-143. All previous treatments had been well-tolerated. Within 2 min of the cycle 3 day 1 infusion she developed severe dyspnea, flushing, and agitation, which progressed to cardiopulmonary arrest despite halting the infusion. The patient was successfully resuscitated and discharged from hospital after a full recovery. Both patients who experienced infusion reactions discontinued treatment with ME-143 and were never rechallenged.

\section{Efficacy}

Seventeen (94\%) patients were evaluable for efficacy. There was no complete or partial responses documented. Three patients had stable disease evident at the first disease evaluation(colorectal cancer $(5 \mathrm{mg} / \mathrm{kg}$ ), anal cancer $(20 \mathrm{mg} / \mathrm{kg}$ weekly), cholangiocarcinoma, $(20 \mathrm{mg} / \mathrm{kg}$ weekly)); however, these patients had all discontinued treatment prior to the second scheduled disease assessment. Fourteen patients had disease progression at their first assessment.

\section{Pharmacokinetics}

Pharmacokinetic parameters for each patient were determined and the mean values $( \pm \mathrm{SD})$ for each cohort

Table 2 Dose escalation and treatment exposure by dose level $(N=18)$

\begin{tabular}{|c|c|c|c|c|c|}
\hline & $\begin{array}{l}2.5 \mathrm{mg} / \mathrm{kg} \\
\text { weekly }(n=3)\end{array}$ & $\begin{array}{l}5 \mathrm{mg} / \mathrm{kg} \\
\text { weekly }(n=3)\end{array}$ & $\begin{array}{l}10 \mathrm{mg} / \mathrm{kg} \\
\text { weekly }(n=3)\end{array}$ & $\begin{array}{l}20 \mathrm{mg} / \mathrm{kg} \\
\text { weekly }(n=6)\end{array}$ & $\begin{array}{l}20 \mathrm{mg} / \mathrm{kg} \text { twice- } \\
\text { weekly }(n=3)\end{array}$ \\
\hline Number of DLTs & 0 & 0 & 0 & 0 & 0 \\
\hline \multicolumn{6}{|l|}{ Maximum treatment cycles completed } \\
\hline 1 & 0 & 0 & 0 & 0 & $1(33 \%)$ \\
\hline 2 & $3(100 \%)$ & $2(67 \%)$ & $3(100 \%)$ & $5(83 \%)$ & $1(33 \%)$ \\
\hline 3 & 0 & 0 & 0 & $1(17 \%)$ & 0 \\
\hline 4 & 0 & $1(33 \%)$ & 0 & 0 & $1(33 \%)$ \\
\hline $\begin{array}{l}\text { Patients requiring dose reduction due } \\
\text { to adverse event }\end{array}$ & 0 & 0 & 0 & 0 & 0 \\
\hline Number of doses held due to adverse event & $2(67 \%)$ & 0 & 0 & 0 & 0 \\
\hline $\begin{array}{l}\text { Number of patients with infusions interrupted } \\
\text { due to infusion reaction }\end{array}$ & 0 & 0 & 0 & $1(17 \%)$ & $1(33 \%)$ \\
\hline $\begin{array}{l}\text { Discontinued treatment due to infusion } \\
\text { reaction }\end{array}$ & 0 & 0 & 0 & $1(17 \%)$ & $1(33 \%)$ \\
\hline
\end{tabular}


Table 3 Treatment-emergent adverse events in $>10 \%$ of patients $(N=18)$

\begin{tabular}{|c|c|c|c|c|c|c|c|c|c|c|c|}
\hline & \multicolumn{2}{|c|}{$\begin{array}{l}2.5 \mathrm{mg} / \mathrm{kg} \text { weekly } \\
(n=3)\end{array}$} & \multicolumn{2}{|c|}{$\begin{array}{l}5 \mathrm{mg} / \mathrm{kg} \text { weekly } \\
(n=3)\end{array}$} & \multicolumn{2}{|c|}{$\begin{array}{l}10 \mathrm{mg} / \mathrm{kg} \text { weekly } \\
(n=3)\end{array}$} & \multicolumn{2}{|c|}{$\begin{array}{l}20 \mathrm{mg} / \mathrm{kg} \text { weekly } \\
(n=6)\end{array}$} & \multicolumn{2}{|c|}{$\begin{array}{l}20 \mathrm{mg} / \mathrm{kg} \text { twice- } \\
\text { weekly }(n=3)\end{array}$} & \multirow[t]{2}{*}{$\begin{array}{l}\text { Total } \\
(N=18)\end{array}$} \\
\hline & Grade $1 / 2$ & Grade 3/4 & Grade $1 / 2$ & Grade 3/4 & Grade $1 / 2$ & Grade 3/4 & Grade $1 / 2$ & Grade $3 / 4$ & Grade $1 / 2$ & Grade $3 / 4$ & \\
\hline Fatigue & $3(100 \%)$ & 0 & $1(33 \%)$ & 0 & 0 & 0 & $2(33 \%)$ & 0 & 0 & 0 & $6(33 \%)$ \\
\hline Diarrhea & $2(67 \%)$ & 0 & $1(33 \%)$ & 0 & 0 & 0 & 0 & 0 & $1(33 \%)$ & 0 & $4(22 \%)$ \\
\hline Nausea & $1(33 \%)$ & 0 & $1(33 \%)$ & 0 & 0 & 0 & $1(17 \%)$ & 0 & $1(33 \%)$ & 0 & $4(22 \%)$ \\
\hline Dyspnea & $1(33 \%)$ & 0 & $1(33 \%)$ & 0 & $1(33 \%)$ & 0 & 0 & $1(17 \%)$ & 0 & 0 & $4(22 \%)$ \\
\hline Headache & $1(33 \%)$ & 0 & $1(33 \%)$ & 0 & 0 & 0 & 0 & 0 & $1(33 \%)$ & 0 & $3(17 \%)$ \\
\hline Anemia & 0 & 0 & $1(33 \%)$ & 0 & 0 & 0 & $1(17 \%)$ & 0 & 0 & 0 & $2(11 \%)$ \\
\hline Anxiety & $1(33 \%)$ & 0 & 0 & 0 & 0 & 0 & $1(17 \%)$ & 0 & 0 & 0 & $2(11 \%)$ \\
\hline Back pain & 0 & 0 & 0 & 0 & $1(33 \%)$ & 0 & $1(17 \%)$ & 0 & 0 & 0 & $2(11 \%)$ \\
\hline Constipation & $1(33 \%)$ & 0 & 0 & 0 & 0 & 0 & 0 & 0 & $1(33 \%)$ & 0 & $2(11 \%)$ \\
\hline Cough & $2(67 \%)$ & 0 & 0 & 0 & 0 & 0 & 0 & 0 & 0 & 0 & $2(11 \%)$ \\
\hline $\begin{array}{l}\text { Decreased } \\
\text { appetite }\end{array}$ & $1(33 \%)$ & 0 & $1(33 \%)$ & 0 & 0 & 0 & 0 & 0 & 0 & 0 & $2(11 \%)$ \\
\hline Dysuria & 0 & 0 & 0 & 0 & 0 & 0 & $1(17 \%)$ & 0 & $1(33 \%)$ & 0 & $2(11 \%)$ \\
\hline Fall & 0 & 0 & 0 & 0 & $1(33 \%)$ & 0 & 0 & 0 & $1(33 \%)$ & 0 & $2(11 \%)$ \\
\hline Hyperglycemia & 0 & 0 & $1(33 \%)$ & 0 & 0 & 0 & 0 & 0 & $1(33 \%)$ & 0 & $2(11 \%)$ \\
\hline Infusion reaction & 0 & 0 & 0 & 0 & 0 & 0 & 0 & $1(17 \%)$ & $1(33 \%)$ & 0 & $2(11 \%)$ \\
\hline Pneumonia & 0 & $2(67 \%)$ & 0 & 0 & 0 & 0 & 0 & 0 & 0 & 0 & $2(11 \%)$ \\
\hline Productive cough & 0 & 0 & 0 & 0 & $1(33 \%)$ & 0 & $1(17 \%)$ & 0 & 0 & 0 & $2(11 \%)$ \\
\hline Vomiting & $1(33 \%)$ & 0 & 0 & 0 & 0 & 0 & 0 & 0 & $1(33 \%)$ & 0 & $2(11 \%)$ \\
\hline
\end{tabular}

summarized in Table 4. Samples from 15 patients were available for PK analysis. PK sample sets were incomplete for three patients, due to missing or hemolyzed samples. The population mean half-lives for the weekly dosing cohorts on Days 1 and 15 were $5.36( \pm 1.23)$ hours and 5.10 $( \pm 1.31)$ hours, respectively. $C_{\max }$ was observed at the end of the $30 \mathrm{~min}$ infusion and increased with increasing dose. Mean $\mathrm{C}_{\max }$ values achieved at the highest dose level $(20 \mathrm{mg} / \mathrm{kg})$ were $40.13 \mu \mathrm{g} / \mathrm{mL}(120 \mu \mathrm{M})$ and $37.48 \mu \mathrm{g} / \mathrm{mL}$ $(112 \mu \mathrm{M})$ on days 1 and 15 , respectively. The inter-patient variability ( $\mathrm{CV} \%$ ) for $\mathrm{C}_{\max }$ at the $20 \mathrm{mg} / \mathrm{kg}$ dose level was $45 \%$ on day 1 and $38 \%$ for day 15 .

ME-143 exposures (AUC) increased in a dose-proportional manner (Fig. 1). There was no statistical difference between dose $(\mathrm{mg} / \mathrm{kg})$ and AUC normalized to dose. The inter-patientvariability for the AUC on days 1 and 15 (17\% and $30 \%$, respectively) was relatively low. The population average for Vdss was $161( \pm 81.75) \mathrm{L}$ on Day 1 and $138( \pm 56.23) \mathrm{L}$ on Day 15. Both clearance $(P=0.236)$ and volume of distribution $(P=0.360)$ values were independent of dose $(\mathrm{mg} / \mathrm{kg})$ by the

Table 4 Mean (SD) pharmacokinetic parameters of ME-143, weekly schedule

\begin{tabular}{|c|c|c|c|c|c|c|}
\hline Dose & $\mathrm{C}_{\max }(\mu \mathrm{g} / \mathrm{mL})$ & $\mathrm{C}_{\min }(\mathrm{ng} / \mathrm{mL})$ & $\mathrm{t}_{1 / 2}(\mathrm{hr})$ & AUC $(\mu \mathrm{g} * \mathrm{hr} / \mathrm{mL})$ & $\mathrm{CL}(\mathrm{L} / \mathrm{hr})$ & Vdss (L) \\
\hline \multicolumn{7}{|l|}{ Day 1} \\
\hline $2.5 \mathrm{mg} / \mathrm{kg}$ & $2.18(1.21)$ & $4.02(1.89)$ & $4.12 *(0.55)$ & $2.96(0.56)$ & $69.73(17.2)$ & $230(105)$ \\
\hline $5 \mathrm{mg} / \mathrm{kg}$ & $8.62(0.32)$ & $34.43(2.89)$ & $6.95 *(0.70)$ & $10.27(1.16)$ & $37.30(10.8)$ & $145(37.1)$ \\
\hline $10 \mathrm{mg} / \mathrm{kg}$ & $10.77(2.31)$ & $16.2(8.97)$ & $5.54 *(1.04)$ & $10.42(1.20)$ & $58.96(1.74)$ & $167(19.8)$ \\
\hline $20 \mathrm{mg} / \mathrm{kg}$ & $40.13(18.2)$ & $37.52(27.99)$ & $5.47 *(1.05)$ & $30.15(5.11)$ & $60.42(25.2)$ & $132(90.7)$ \\
\hline \multicolumn{7}{|l|}{ Day 15} \\
\hline $2.5 \mathrm{mg} / \mathrm{kg}$ & $3.55(1.09)$ & $6.12(4.57)$ & $4.36 *(0.92)$ & $3.57(0.31)$ & $56.18(3.75)$ & $177(40.5)$ \\
\hline $5 \mathrm{mg} / \mathrm{kg}$ & $8.94(6.29)$ & $15.93(4.43)$ & $5.12 *(0.85)$ & $9.47(3.58)$ & $41.32(7.33)$ & $121(28.6)$ \\
\hline $10 \mathrm{mg} / \mathrm{kg}$ & $17.61(6.93)$ & $11.83(5.62)$ & $4.89 *(0.66)$ & $12.62(3.93)$ & $59.41(22.08)$ & $114(58.5)$ \\
\hline $20 \mathrm{mg} / \mathrm{kg}$ & $37.48(14.4)$ & $43.21(27.74)$ & $5.64 *(2.21)$ & $29.61(8.88)$ & $61.43(20.9)$ & $141(71.1)$ \\
\hline
\end{tabular}

*Harmonic mean 
non-parametric Kruskal-Wallis ANOVA. There was no statistical difference between clearance and volume of distribution values on days 1 and 15 . The clearance and volume of distribution values for patients receiving $20 \mathrm{mg} / \mathrm{kg}$ twice-weekly dosing approximated those observed in patients receiving $20 \mathrm{mg} / \mathrm{kg}$ weekly (data not shown).

\section{Discussion}

Weekly administration of ME-143 was generally welltolerated in this first-in-human study of patients with refractory solid tumors. There were no dose-limiting toxicities observed, and while there was no formal MTD defined, the maximally administered dose was $20 \mathrm{mg} / \mathrm{kg}$ weekly. Following the life threatening infusion reaction during cycle 3 of a patient receiving $20 \mathrm{mg} / \mathrm{kg}$ biweekly, coupled with concurrent preclinical studies that demonstrated no incremental efficacy improvements with biweekly dosing, the decision was made to cease further enrollment to the biweekly cohort. The most common adverse events related to ME-143 across all dose levels were fatigue and nausea, all grade 1 or 2 .

While ME-143 was well-tolerated by most patients, two patients experienced infusion reactions to ME-143. The exact cause of these infusion reactions is not clear; however, it may be related to the high osmolarity of the final solution for drug administration. Depending on the degree of dilution prior to administration, the ME-143 drug product can result in hyperosmolar infusion solutions, particularly in large patients (by weight) receiving the highest administered dose level $(20 \mathrm{mg} / \mathrm{kg})$. The two patients with infusion reactions had delivered osmolarities of 0.67 and $0.74 \mathrm{Osm} / \mathrm{L}$. The intravenous delivery of hyperosmolar solutions has well described risk for basophilic histamine release and clinical

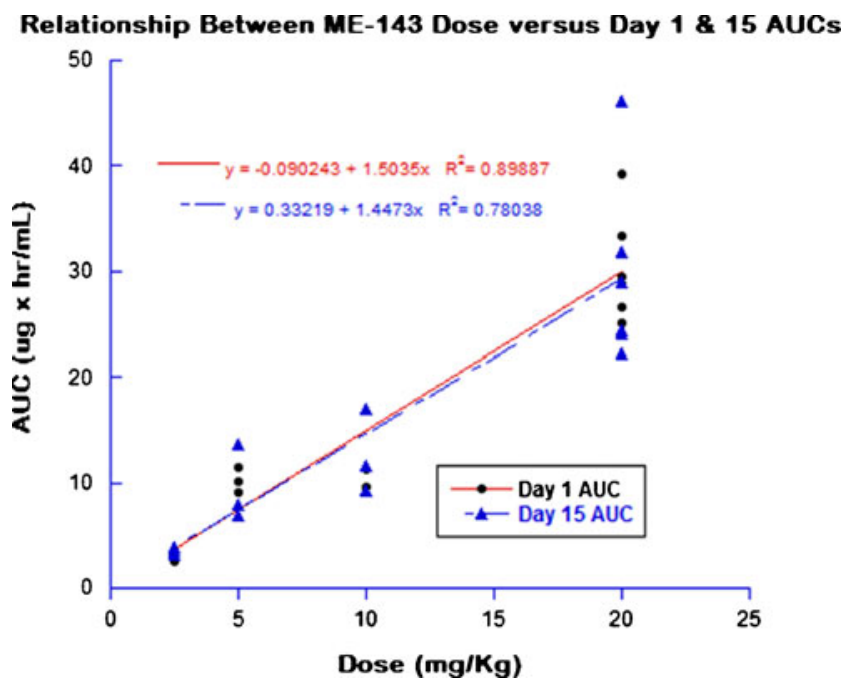

Fig. 1 ME-143 Dose versus Day 1 and Day 15 AUCs anaphylactic-like infusion reactions [10]. Following the observance of these infusion reactions, ME-143 administration instructions were modified, by protocol amendment, to keep the osmolarity of the infusion limited to $0.5 \mathrm{Osm} / \mathrm{L}$. No further infusion reactions were noted, although few infusions were administered under these revised instructions. Future studies will need to monitor this adverse event closely as ME-143 moves further in development.

Pharmacokinetic analysis revealed that ME-143 plasma concentrations decline in a multi-exponential fashion with a harmonic mean half-life of approximately $5 \mathrm{~h}$. A linear relationship was observed between ME-143 dose ( $\mathrm{mg} / \mathrm{kg}$ ) and $\mathrm{C}_{\max }$ levels and exposure (AUC) levels on days 1 and 15. Volume of distribution and clearance values were independent of ME-143 dose and there were no statistical differences in these parameters between days 1 and 15 . Unfortunately, a suitable clinical biomarker has not been identified to help confirm the adequacy of the exposures observed at the $20 \mathrm{mg} / \mathrm{kg}$ weekly dose.

There were no objective responses to ME-143 documented in this study. Three patients with gastrointestinal cancers, two of whom were receiving $20 \mathrm{mg} / \mathrm{kg}$ weekly, had stable disease evident at the first disease assessment but progressed prior to the second disease assessment. However, in vitro studies with ME-143 demonstrated synergistic activity with various chemotherapy agents (carboplatin, cisplatin, gemcitabine, paclitaxel, doxorubicin, dacarbazine) in a variety of cancer cell lines (ovarian, prostate, colorectal, melanoma, glioma, lung, breast, and pancreas). This in vitro interaction has also been confirmed in in vivo xenograft models [MEI Pharma, Inc, data on file]. Based on the promising signal observed with IV phenoxodiol in ovarian cancer, further phase II development of ME-143 will be conducted in combination with cytotoxic chemotherapy.

In conclusion, ME-143 was reasonably well-tolerated when administered on a once weekly schedule. With no dose limiting toxicities, the maximally administered dose of $20 \mathrm{mg} / \mathrm{kg}$ once weekly is the dose recommended for further study. Though this is the recommended phase II dose as defined by the protocol, the design of future studies will need to include careful guidelines for monitoring and management of infusion reactions, and to confirm that the modified ME-143 administration instructions ameliorate this adverse event. Pharmacokinetic exposures at this dose demonstrated that drug levels achieved target concentrations determined from preclinical studies to be efficacious. Although minimal clinical activity was observed, it is likely that inhibitors of tNOX such as ME-143 will derive their greatest benefit in combination.

Conflicts of interest S. Pant and K. Moore have an advisory role with MEI Pharma, Inc. O. Moreno is employed by and holds stock in MEI Pharma, Inc. J. Kuhn is a consultant with MEI Pharma, Inc. No potential conflicts of interest were disclosed by the other authors. 
Open Access This article is distributed under the terms of the Creative Commons Attribution License which permits any use, distribution, and reproduction in any medium, provided the original author(s) and the source are credited.

\section{References}

1. Morre D, Chueh P, Yagiz K et al (2007) ECTO-NOX target for the anticancer isoflavone Phenoxodiol. Oncol Res 16:299-312

2. Silasi D-A, Alvero AB, Rutherford TJ et al (2009) Phenoxodiol: pharmacology and clinical experience in cancer monotherapy and in combination with chemotherapeutic drugs. Expert Opin Pharmacother 10:1059-1067

3. Kelly M, Mor G, Husband A et al (2011) Phase II evaluation of phenoxodiol in combination with cisplatin or paclitaxel in women with platinum/taxane-refractory/resistant epithelial ovarian, fallopian tube, or primary peritoneal cancers. Int J Gynecol Cancer 21:633-639
4. Herst P, Peterson T, Jerram $P$ et al (2007) The antiproliferative effects of phenoxodiol are associated with inhibition of plasma membrane electron transport in tumour cell lines and primary immune cells. Biochem Pharmacol 74:1587-1595

5. Wang X, McKernan R, Kim K et al (2011) Triphendiol (NV-196), development of a novel therapy for pancreatic cancer. Anticancer Drugs 22:719-731

6. Declaration of Helsinki. In. www.wma.net/e/ethicsunit/ helsinki.htm: World Medical Association, Ethics Unit 2007

7. Storer BE (1989) Design and analysis of phase I clinical trials. Biometrics 45:925-937

8. NCI Common Terminology Criteria for Adverse Events (CTCAE) v.4. In. http://evs.nci.nih.gov/ftp1/CTCAE/about.html: National Cancer Institute

9. Eisenhauer E, Therasse P, Bogaerts J et al (2009) New Response Evaluation Criteria in Solid Tumors: Revised RECIST Guideline (version 1.1). Eur J Cancer 45:228-247

10. Findlay SR, Dvorak AM, Kagey-Sobotka A, Lichtenstein LM (1981) Hyperosmolar Triggering of Histamine Release from Human Basophils. J Clin Invest 67:1604-1613 